\title{
Crossing the gender divide
}

\begin{abstract}
A program at the US National Science Foundation (NSF) has tackled the problem of the under-representation of women in academic bioscience by providing grants to foster institutional change. A recent study shows that more progress is needed—but universities and other research centers can make a big difference in sometimes small ways.
\end{abstract}

A $\mathrm{n}$ equivalent number of men and women currently receive graduate degrees in biology in the US, but a study released in April surveying bioscience faculty members at the 50 top National Institutes of Health-funded universities shows that the percentage of female faculty members is just $27 \%$ (Acad. Med. 85, 631-639, 2010).

The NSF has had its eye on this problem, and since 2001 it has funded \$130 million in ADVANCE grants at over 100 universities with the goal of increasing the recruitment and participation of women on science faculties. The grantees have used the funding to devise and implement ways to increase the representation of women faculty on their campuses. Although the new study shows that there is still a long way to go to achieve gender equity on life sciences faculties, the early results of the ADVANCE program have been promising and could serve as a template for other institutions.

One of the first institutional recipients of ADVANCE funding was the University of Michigan-Ann Arbor. After a detailed assessment of how male and female faculty members perceive the amount of research and career support they receive from colleagues, departments and the university as a whole, administrators realized that some practices needed to be changed.

Several programs were put in place to change the institutional climate, ranging from university-wide changes in hiring procedures to measures calling for each department to closely examine gender equity. For example, departments had to ensure that the diversity of the job candidates granted interviews reflected the diversity of the applicant pool. Assessments of job candidates also became more formalized by including information about how much time the interviewer spent with the interviewee and details about the interviewee's strengths and weaknesses. After these and other practices were enacted, the percentage of female new hires in science went from $14 \%$ in $2001-2002$ to $34 \%$ in 2003-2006.

Individual departments at the University of Michigan were also encouraged to examine their own specific problems with achieving gender equity — such as difficulty in retaining women faculty - and to apply for grants from the university that would then also provide training to help effect change. One department realized that interactions between a new hire and established faculty were more likely to be positive and beneficial if the new hire fit in with the key specialties of the department, as opposed to bringing in a female scientist with a new and unrelated research focus. The university also began a research grant program open to female faculty and provided leadership training for these professors. Since putting into effect institutional, departmental and personal changes after receiving the ADVANCE grant, the percentage of female full professors in the basic research faculty of the medical school increased from 18\% in 2001 to $27 \%$ in 2009 .

The University of Michigan also used funds from the NSF ADVANCE grant to equalize gender disparities in salary and to provide administrators with up-to-date information about the representation of women in departments and schools across the university.

Nevertheless, in 2009, after 8 years of ADVANCE grant support, only $30 \%$ of the university's tenure-track life sciences faculty members are women. Furthermore, even though the ADVANCE grant program was put into effect at many research institutions across the country, the Academic Medicine study indicates that women are still under-represented on bioscience faculties and that pay disparities still run rampant-female faculty members made about $\$ 13,000$ less per year than male faculty members with equivalent academic ranking.

Institutional change takes time, so it may be unreasonable to expect that the representation of women on science faculties would reach $50 \%$ in less than 10 years, even with a strong push from the NSF. But some of these programs — such as changing faculty recruiting practices, providing information about faculty gender percentages to administrators and providing leadership training for female professors-cost little or no money. More widespread adoption of these measures by university administrators could help women finally become equal partners in the scientific enterprise. 